\title{
DEGRADAÇÃO DO SOLO POR EROSÃO EM ÁREA VULNERÁVEL À DESERTIFICAÇÃO NO SEMIÁRIDO PERNAMBUCANO
}

\author{
Manuella Vieira Barbosa Neto ${ }^{(a)}$, Maria do Socorro Bezerra de Araújo ${ }^{(b)}$, José Coelho de \\ Araújo Filho ${ }^{(\mathrm{c})}$, Brivaldo Gomes de Almeida ${ }^{(\mathrm{d})}$ \\ (a) Docente do Curso de Licenciatura em Geografia, IFPE, manuellaneto@ recife.ifpe.edu.br \\ (b) Docente do Departamento de Ciências Geográficas, UFPE, socorro@ufpe.br \\ (c) Pesquisador da Embrapa Solos UEP - Recife, jose.coelho@embrapa.br \\ (d) Docente do Departamento de Agronomia - UFRPE, brivaldo@depa.ufrpe.br
}

\section{EIXO: SOLOS E PAISAGENS}

\begin{abstract}
Resumo
Este trabalho objetivou realizar um levantamento da degradação dos solos por erosão no município de Itacuruba - PE. A erosão dos solos é reconhecida como uma das principais causas da degradação dos solos, entre outros fatores, em razão de seu caráter de irreversibilidade. O município de Itacuruba localiza-se na microrregião de Itaparica no Sertão de Pernambuco e é incluído no núcleo de desertificação de Cabrobó-PE pela ONU. O levantamento da intensidade dos processos erosivos baseou-se nas observações realizadas nos trabalhos de campo, em 94 pontos da área de estudo. Também foram realizadas medições nos sulcos encontrados. Foram medidos a largura, a profundidade e o comprimento médio em 70 pontos. Nos principais solos do município, há processos erosivos que variaram de moderado a forte em $84 \%$ dos pontos avaliados. A erosão em sulcos também é frequente, com destaque para a ocorrência nos Planossolos e Luvissolos.
\end{abstract}

Palavras Chave: Dinâmica erosiva, medidas de erosão e paisagem semiárida.

\section{Introdução}

A Convenção das Nações Unidas de Combate à Desertificação indica a degradação da terra como um dos principais agentes causadores da desertificação. Entre os atributos da degradação da terra, a erosão dos solos e a deterioração de suas propriedades física, química e biológica são muito preocupantes, pois impactam o rendimento das lavouras, tornando alto o custo de produção; além de causar problemas referentes à segurança alimentar da população local.

A erosão dos solos é reconhecida como uma das principais causas da degradação dos solos, entre outros fatores, em razão de seu caráter de irreversibilidade. Um grave problema do processo erosivo consiste na eliminação da camada superficial do solo, rica em matéria orgânica e partículas minerais finas, que garantem a nutrição necessária ao crescimento dos vegetais.

Segundo Lal (2003), a erosão geológica lenta é um processo construtivo, que criou várias extensões de solos férteis em todo mundo. Em contraste, a erosão acelerada do solo, intensificada por ações antropogênicas, é um processo destrutivo. Diminui a fertilidade do solo, degrada a estrutura do mesmo, reduz a profundidade efetiva de enraizamento e destrói o mais básico de todos os recursos naturais. Segundo o autor supracitado, a erosão acelerada tem importunado a humanidade desde o início da agricultura assentada, com diversos relatos na literatura sobre os seus efeitos adversos. 
Em especial, no ambiente semiárido, os mantos de intemperismo são pouco espessos e são consequência de um balanço denudacional que beneficia a erosão sobre os agentes pedogenéticos (CORRÊA; SOUZA; CAVALCANTI, 2014). Uma elevada proporção dos solos do semiárido tem um baixo potencial produtivo e elevada vulnerabilidade à erosão, seja por suas limitações de drenagem, seja pelo baixo teor de carbono orgânico (GIONGO et al., 2011).

As ações antrópicas que buscam utilizar os solos do ambiente Semiárido para fins agrícolas muitas vezes não obtêm sucesso, pelas limitações dos solos ou o uso incorreto, o que leva ao abandono de áreas cujo solo está sem a proteção original da vegetação nativa. Sendo assim, os solos da região semiárida, na maioria de baixa qualidade, são atingidos por processos de degradação da terra, como o desmatamento que retira a vegetação nativa e, consequentemente, a proteção do solo, aumentando a sua vulnerabilidade à erosão e contribuindo na redução da sua qualidade. Segundo Marzolff et al. (2015), as regiões semiáridas de todo mundo são particulamente vulneráveis ao efeitos do crescimento populacional e às mudanças do uso da terra. Nessas áreas a erosão hídrica é um importante processo de degradação do solo.

Ainda são incipientes dados precisos sobre perdas de solo no Nordeste do Brasil, exceto em áreas experimentais, conforme Sampaio et al. (2003). Esses autores afirmaram que se têm utilizado dados indiretos como a presença de voçorocas, sendo correto quantificá-las para precisar seu aumento em número, extensão ou profundidade. Na carência dessas informações, deve-se aceitar a estimativa visual por técnicos e agricultores com experiência na área.

O município de Itacuruba localiza-se na microrregião de Itaparica no sertão pernambucano, e é incluído no núcleo de desertificação de Cabrobó-PE pela ONU. Sendo assim, já é apontado como uma área que sofre intenso processo de degradação ambiental, sendo importante compreender o estágio de degradação em que essa área se encontra e verificar os impactos causados nos solos desse município. Nesse sentido, este trabalho objetivou realizar um levantamento do estado de degradação dos solos por erosão no município de Itacuruba - PE, para desse modo contribuir com o planejamento de ações que visem mitigar os seus efeitos.

\section{Material e Métodos}

\subsection{Caracterização da Área de estudo}

O município de Itacuruba localiza-se na microrregião de Itaparica no sertão pernambucano. A área municipal é de $436,7 \mathrm{~km}^{2}$. De acordo com o Instituto Brasileiro de Geografia e Estatística (IBGE, 2015), o município tem uma população de 4.700 habitantes, com uma densidade demográfica de 10,76 hab./km². Encontra-se inserido no núcleo de desertificação de Cabrobó (Figura 1) de acordo com o mapeamento realizado pelo MMA do Brasil (BRASIL, 1998b). 

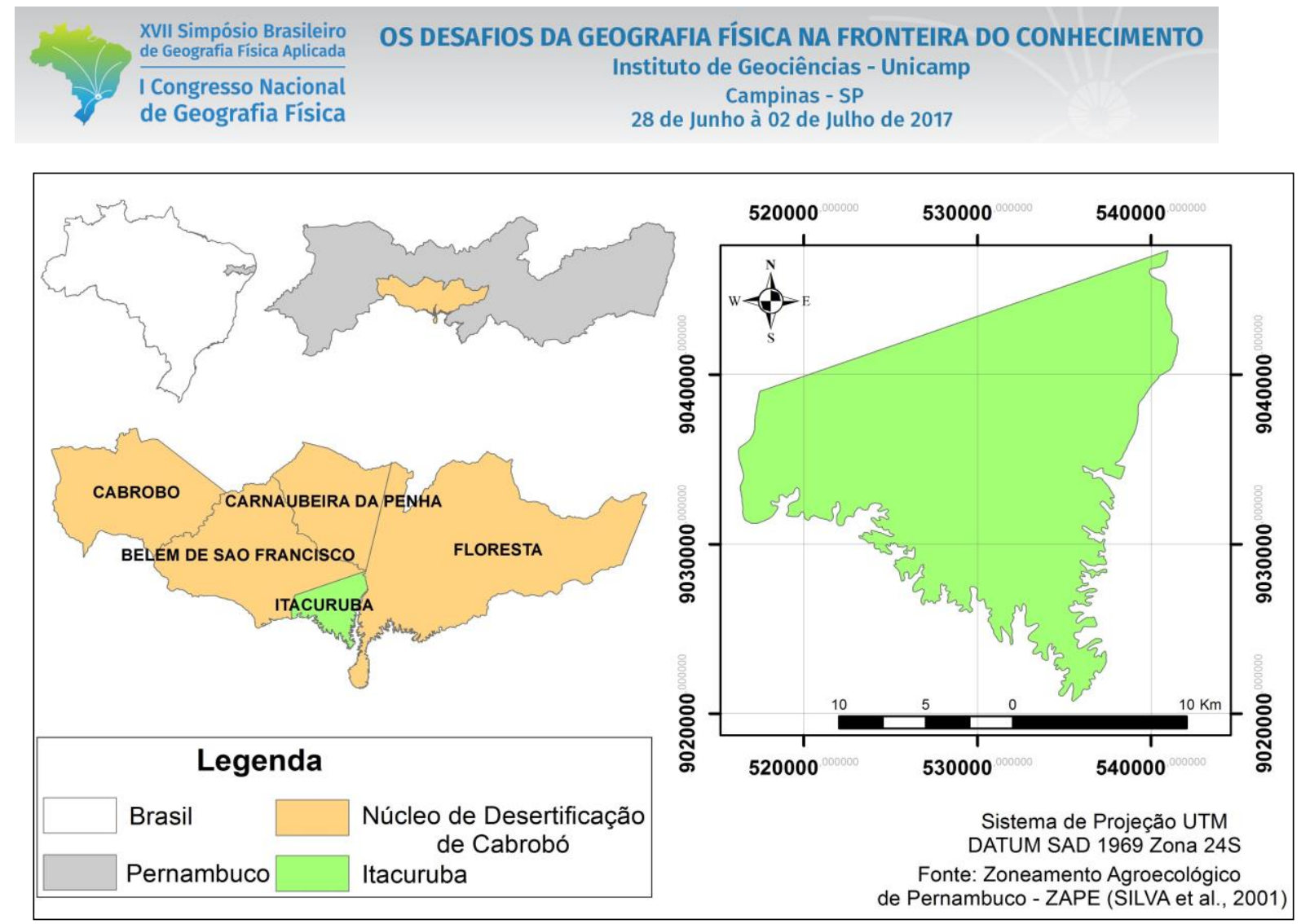

Figura 1 - Localização geográfica do município de Itacuruba, no núcleo de desertificação de Cabrobó pernambucano

O município está inserido, geologicamente, na Província Borborema e na unidade geoambiental da Depressão Sertaneja (BELTRÃO et al., 2005). Apresenta um relevo predominantemente suave ondulado e plano, com cotas altimétricas que variam entre 296 e 472 metros. O clima é do tipo tropical semiárido, com chuvas de verão tendo média anual em torno de $430 \mathrm{~mm}$. Na área, são encontradas as seguintes classes de solos: Luvissolo, Planossolo, Neossolo Regolítico, Neossolo Flúvico e Neossolo Litólico (SILVA et al., 2001). Está nos domínios da macrobacia hidrográfica do rio São Francisco, da bacia hidrográfica do rio Pajeú e do Grupo de Bacias de Pequenos Rios Interiores. A vegetação da região é a Caatinga Hiperxerófila, com porte predominantemente arbustivo-herbáceo, onde são observados muitos espaços desprovidos de cobertura vegetal.

\subsection{Metodologia}

O levantamento dos processos erosivos que estão atingindo os solos da área de estudo foi realizado, principalmente, com base no reconhecimento da área de estudo. Foram coletadas informações sobre as classes de solo (EMBRAPA 2013), estado da vegetação, uso da terra e classes de erosão nos anos de 2014, 2015 e início de 2016, em 163 pontos devidamente georreferenciados, nos locais que permitiam o acesso. Foi utilizada como base cartográfica informações da imagem do Satélite Landsat 8, de janeiro de 2014 (Figura 2). 


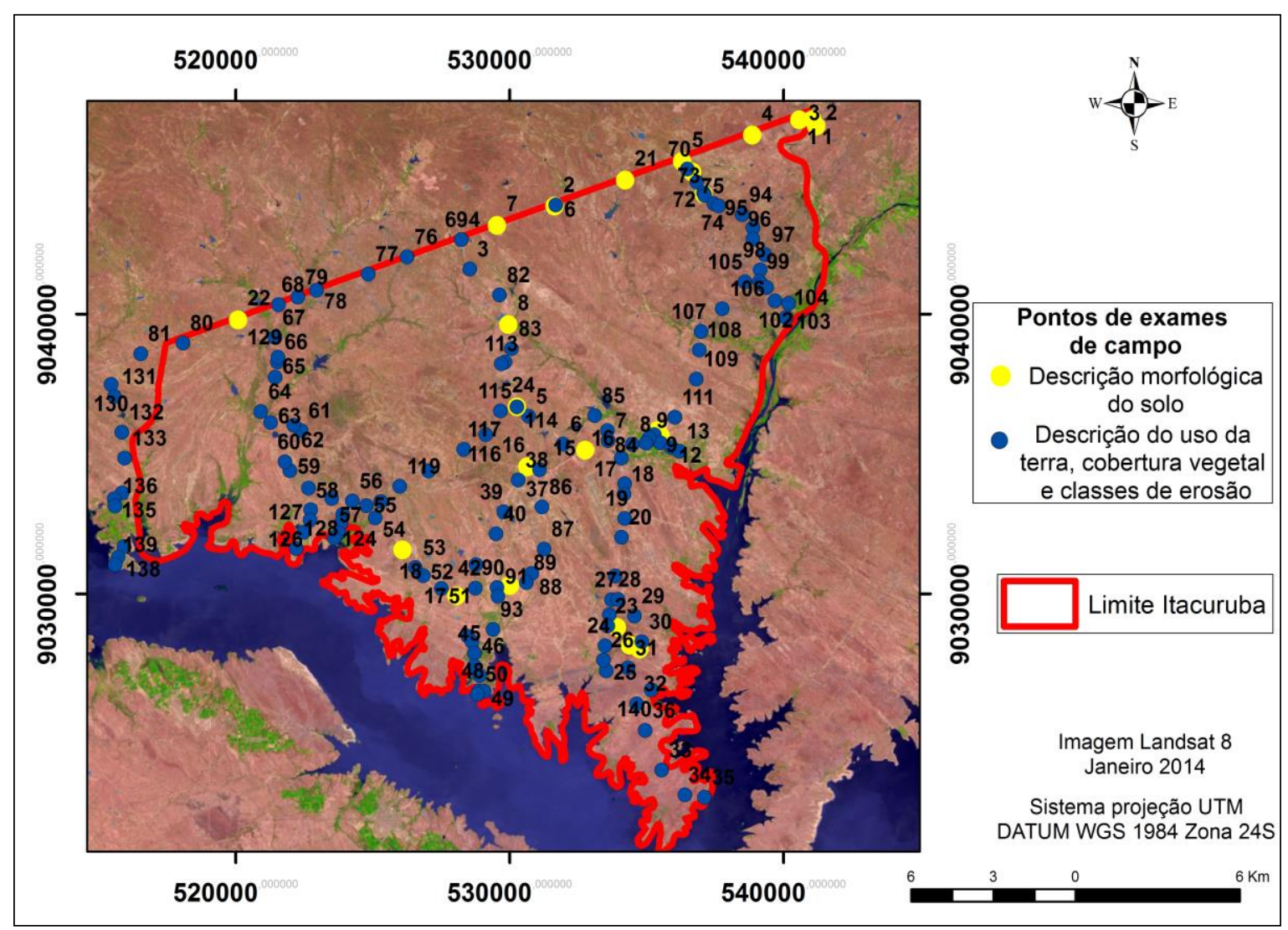

Figura 2 - Imagem do Satélite Landsat 8, do dia 8 de janeiro de 2014, utilizada como base cartográfica, e pontos visitados no município de Itacuruba, microrregião de Itaparica no Sertão pernambucano

Para utilização da imagem, realizou-se por meio do software Arc Gis 9.3 (Gentilmente disponibilizado pelo SERGEO - DCG - UFPE) uma fusão da banda 8 pancromática (tons de cinza), que tem 15 metros de resolução, com as outras 10 bandas multiespectrais (coloridas) de $30 \mathrm{~m}$. Desse modo, a resolução espacial ficou com 15 metros. Nos trabalhos de campo, realizaram-se observações em que se buscou identificar as diferentes classes de erosão (Tabela I), baseando-se em Santos et al. (2005) em 94 pontos da área de estudo.

Tabela I - Classes de erosão utilizadas na avaliação espacial dos processos erosivos no município de Itacuruba, microrregião de Itaparica no Sertão pernambucano

\section{Classes de erosão}

\section{Características}

\begin{tabular}{|c|c|}
\hline Não aparente & $\begin{array}{l}\text { O solo nesta classe não apresenta sinais perceptíveis de erosão eólica, } \\
\text { laminar ou em sulcos. }\end{array}$ \\
\hline Ligeira & $\begin{array}{l}\text { O solo teve menos de } 25 \% \text { do horizonte A removido (incluindo } A B \text { ou } \\
\text { A+E originais com menos de } 20 \mathrm{~cm} \text { de espessura. Apresenta sulcos } \\
\text { ocasionais }{ }^{1} \text {, superficiais }{ }^{2} \text { ou rasos }{ }^{3} \text {. }\end{array}$ \\
\hline Moderada & O solo teve de $25 \%$ a $75 \%$ do horizonte $A$ (incluindo $A B$ ou $A+E$ ) \\
\hline
\end{tabular}


Forte

Muito forte

Extremamente forte removido na maior parte da área. Pode apresentar frequentes ${ }^{4}$ sulcos rasos que são desfeitos pelas práticas normais de preparo do solo.

$\mathrm{O}$ solo teve mais de $75 \%$ do horizonte $\mathrm{A}$ (incluindo $\mathrm{AB}$ ou $\mathrm{A}+\mathrm{E}$ ) removido na maior parte da área. Em terrenos com erosão em sulcos, esses são profundos ${ }^{5}$ ou rasos e muito frequentes ${ }^{6}$. Os sulcos não são desfeitos pelas práticas de preparo do solo e podem ocorrer voçorocas ocasionais.

O solo teve o horizonte $\mathrm{A}$ ou $\mathrm{A}+\mathrm{E}$ totalmente removido. $\mathrm{O}$ horizonte B exposto na superfície do terreno, já foi bastante removido por frequentes sulcos profundos e, ou, voçorocas ${ }^{7}$ e ocasionais sulcos muito profundos e, ou, voçorocas.

O solo apresenta os horizontes A e B completamente removidos, e o horizonte $\mathrm{C}$ revela ocorrência muito frequente de sulcos muito profundos (voçorocas).

Nota: Quanto à frequência e profundidade dos sulcos: 1 - ocasionais - quando a distância entre os sulcos é superior a $30 \mathrm{~m} ; 2$ - superficiais - podem ser cruzados por máquinas agrícolas, sendo desfeitos pelas práticas normais de preparo do solo; 3 - rasos - apresentam profundidade menor do que a largura e podem ser cruzados por máquinas e desfeitos pelas práticas normais de preparo do solo; 4 - frequentes - quando a distância entre os sulcos é inferior a $30 \mathrm{~m}$, ocupando menos de $75 \%$ da área; 5 - profundos - apresentam até 2 $\mathrm{m}$ de profundidade, sendo esta, em geral, maior que a largura e não pode ser cruzado por máquinas agrícolas; 6 - muito frequentes - quando os sulcos ocupam mais de $75 \%$ da área do terreno e a distância entre eles é menor do que $30 \mathrm{~m} ; 7$ - voçorocas ou sulcos muito profundos - ultrapassam a profundidade de $2 \mathrm{~m}$. Fonte: Adaptado de Santos et al. (2005).

$\mathrm{Na}$ área, também foram realizadas medições nos sulcos encontrados. Foram medidos a largura, a profundidade e o comprimento médio desses sulcos em 70 pontos que apresentaram essa característica de degradação. Esses dados foram organizados em quatro grupos de acordo com a proximidade geográfica entre os pontos. Desse modo, foi possível identificar a incidência da erosão em sulcos na área de estudo.

\section{Resultados e Discussão}

Com o reconhecimento da área de estudo, foi realizado o mapeamento do uso da terra (Figura 3a). Observou-se que predomina a cobertura da terra com caatinga arbustiva - herbácea de esparsa a rala com a presença de clareiras, e uma pequena utilização da terra com práticas agrícolas (BARBOSA NETO; ARAÚJO; ARAÚJO FILHO, 2015). Nessas áreas foi observada uma caatinga com porte baixo e presença de grandes espaços entre os arbustos. Portanto, no município predomina uma caatinga visivelmente impactada pelos processos de degradação da terra. A redução da cobertura vegetal contribui, entre outros fatores, para maior vulnerabilidade a processos erosivos; esses, por sua vez, desencadeiam a redução da fertilidade do solo (ADIMASSU et al., 2013). Em consequência, tem-se 
uma redução da biodiversidade na caatinga que é um dos graves problemas no contexto das regiões do semiárido brasileiro (TRIGUEIRO; OLIVEIRA; BEZERRA, 2009).

Em 94 pontos da área de estudo, foram estimadas as classes de erosão. Em 10 pontos, havia erosão ligeira, tendo sido removidos até $25 \%$ do horizonte A, ou dos 20 primeiros centímetros do solo (Figura 3b). Em 49 pontos, predominou erosão moderada, com perda do horizonte A entre 25 e $75 \%$, além da presença de sulcos rasos que não são desfeitos pelo manejo do solo (Figura 3c). Erosão forte foi identificada em 15 pontos, caracterizada pela perda de mais de $75 \%$ do horizonte A, e sulcos frequentes, podendo ser profundos ou rasos (Figura 3d). Em outros 15 pontos, a erosão variou entre moderada e forte. Em 5 pontos, havia uma erosão muito forte, tendo sido o horizonte A totalmente removido, ficando exposto na superfície do terreno o horizonte $\mathrm{B}$, com a presença de sulcos frequentes e profundos (Figura 3e).
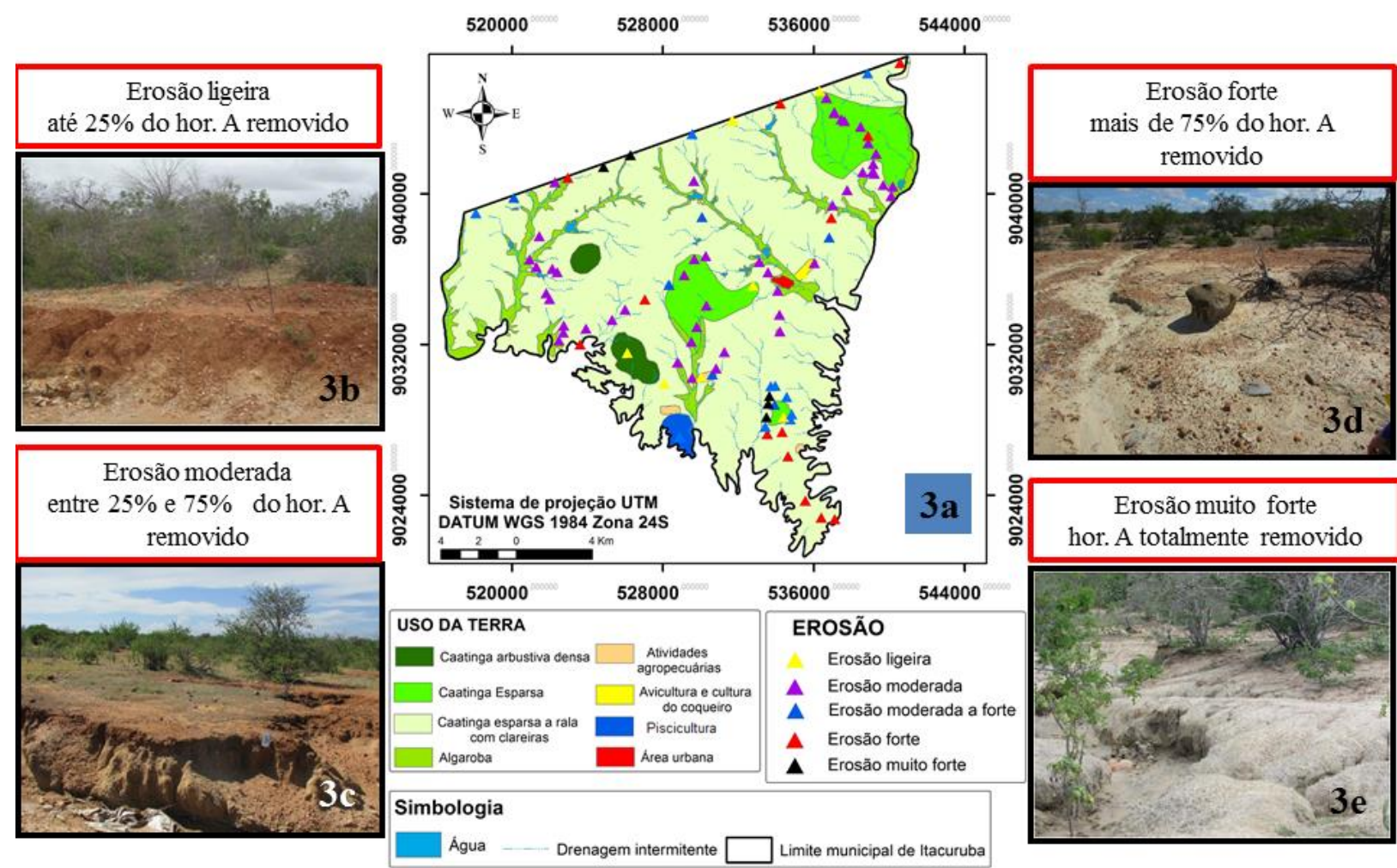

Figura 3 - Classes de erosão observadas no município de Itacuruba, microrregião de Itaparica no Sertão pernambucano Nota: (3a) classes de erosão espacializadas sobre o mapa de uso; (3b) erosão ligeira; (3c) erosão moderada; (3d) erosão forte; (3e) erosão muito forte.

Desse modo predomina nessa área um processo de erosão que varia de moderado a forte. Essas características foram observadas em $84 \%$ dos pontos avaliados. Kairis et al. (2014), ao estudarem o processo de desertificação em 13 locais espacializados pela Europa, Ásia, África, América do Sul e do Norte, afirmaram que a erosão do solo é um importante processo de degradação da terra e 


$\begin{aligned} & \text { XVII Simpósio Brasileiro } \\ & \text { de Geografia Fisica Aplicada }\end{aligned}$
$\begin{aligned} & \text { I Congresso Nacional } \\ & \text { de Geografia Física }\end{aligned}$

desertificação, e observaram erosão moderada em 33,6\% dos pontos de amostragem, enquanto em $24 \%$ dos sítios ocorreu erosão forte.

Itacuruba apresentou forte presença de erosão em sulcos, que se configura em um estágio mais avançado do processo erosivo. Segundo Bezerra et al. (2010), a erosão em sulcos é a segunda fase do processo evolutivo da erosão hídrica do solo, que inicia difuso na camada superficial do solo e avança para pequenas depressões da superfície do solo.

Na Figura 4a, é possível observar a descrição das medidas médias de comprimento, largura e profundidade de 16 sulcos encontrados no Nordeste do município (Figura 5a). Mediram-se 8 sulcos no domínio dos Neossolos Litólicos, com comprimento que variou de 7 a 20 m, largura de 1,6 a $5 \mathrm{~m}$ e profundidade de 0,2 a 0,3 m. Nos Planossolos, realizaram-se 4 medições com comprimentos que variaram entre 4 e $20 \mathrm{~m}$, larguras entre 2 e $6 \mathrm{~m}$ e profundidades entre 0,3 e 0,5 m. Nos Luvissolos, avaliaram-se 4 sulcos, com comprimento variando entre 4 e $18 \mathrm{~m}$, largura entre 0,6 e $1 \mathrm{~m}$ e profundidade entre 0,1 e $0,3 \mathrm{~m}$. Exemplos dos sulcos dessa área podem ser visualizados nas Figuras $5 \mathrm{f}$ e $5 \mathrm{~g}$.
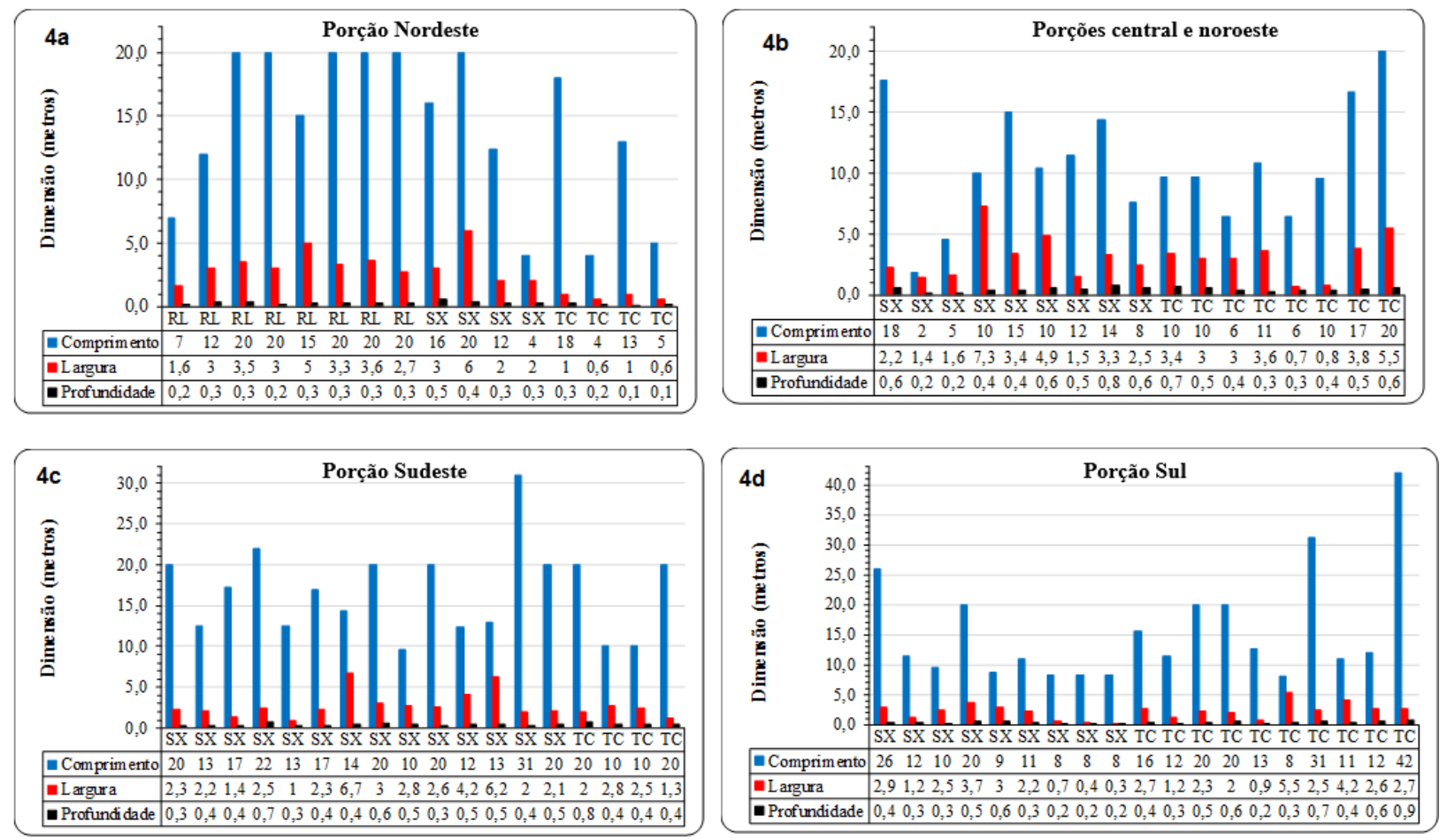

Figura 4 - Resultados das medidas médias de comprimento, largura e profundidade em metros dos sulcos encontrados no município de Itacuruba, microrregião de Itaparica no Sertão pernambucano

Abreviaturas: RL - Neossolo Litólico; SX - Planossolo; TC - Luvissolo. Nota: (4a) medições realizadas na porção nordeste; (4b) medições realizadas nas porções central e noroeste; (4c) medições realização na porção sudeste; (4d) medições realizadas na porção sul.

Na porção central e noroeste do município (Figura 5a), realizaram-se 17 medições em sulcos. Foram 9 em Planossolos e 8 em Luvissolos (Figura 4b). Nos primeiros, os comprimentos variaram entre 2 e 18 
$\mathrm{m}$, as larguras entre 1,4 e 7,3 m e as profundidades entre 0,2 e $0,8 \mathrm{~m}$. Nos segundos, os comprimentos variaram entre 6 e $20 \mathrm{~m}$, as larguras entre 0,8 e 5,5 m e a profundidades entre 0,3 e 0,7 m. Nas Figuras 5 b e 5c, são observados alguns exemplos dos sulcos dessas áreas.

No sudeste do município, realizaram-se 18 medições em sulcos, sendo 14 nos Planossolos e 4 nos Luvissolos (Figura 4c). Nos primeiros, as medidas variaram entre 10 e $31 \mathrm{~m}$ de comprimento, entre 1 e 6,7 m de largura e entre 0,3 e 0,7 m de profundidade. No segundo, as medidas apresentaram uma variação no comprimento entre 10 e 20 m no comprimento, entre 1,3 e 2,8 na largura e entre 0,4 e 0,8 na profundidade. Exemplos desses sulcos podem ser observados nas Figuras 5d e 5e.

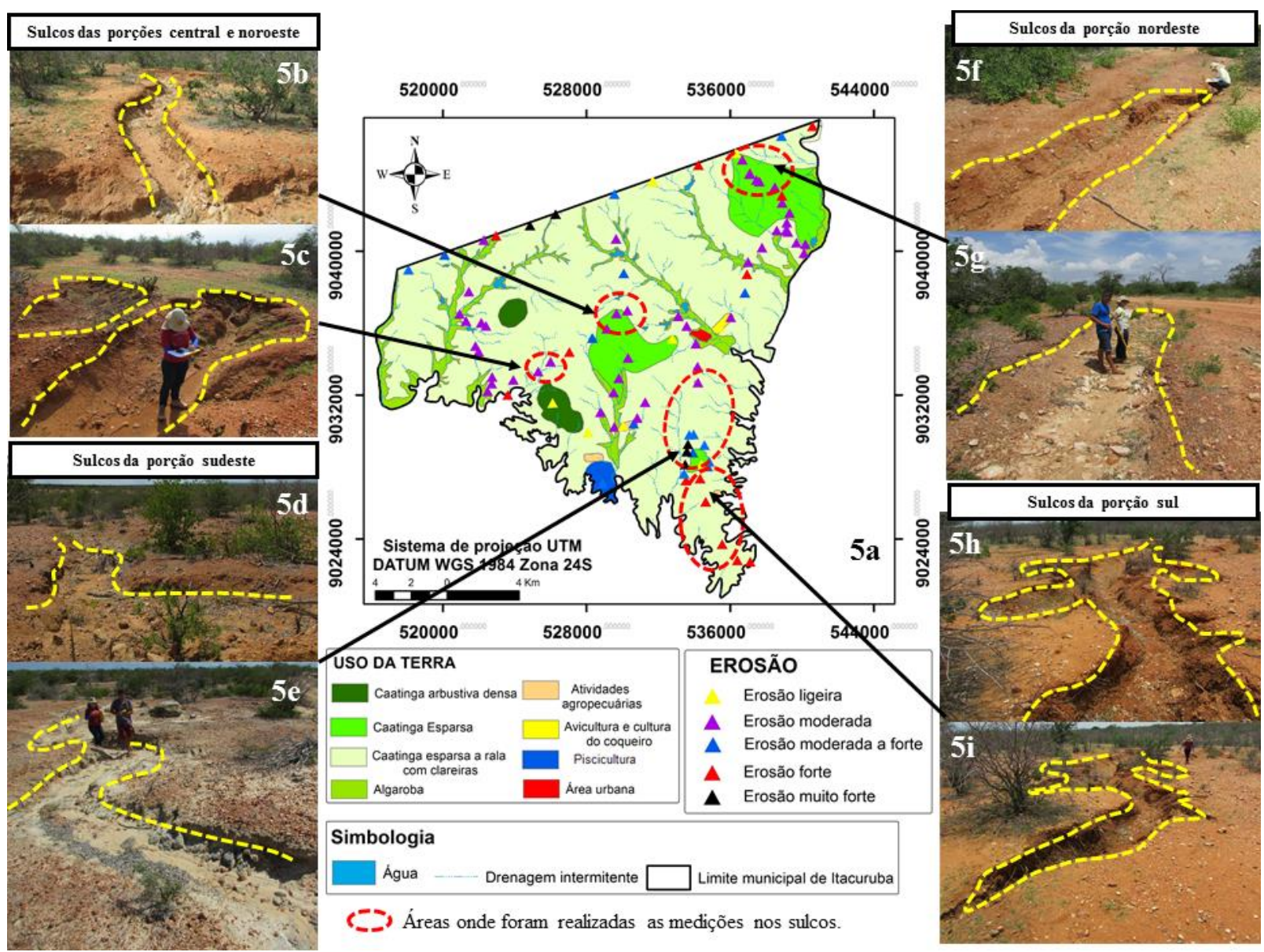

Figura 5 - Identificação das áreas onde foram realizadas as medições de comprimento, largura e profundidade nos sulcos, nas porções, nordeste, central, noroeste, sudeste e sul do município de Itacuruba, microrregião de Itaparica no Sertão pernambucano. Nota: (5a) - classes de erosão espacializadas sobre o mapa de uso, com a identificação das áreas onde foram realizadas as medições dos sulcos; (5b) - sulco em Planossolo na porção central de Itacuruba; (5c) - sulco em Luvissolo na porção noroeste de Itacuruba; (5d) - sulco em Luvissolo na porção sudeste de Itacuruba; (5e) - sulco em Planossolo na porção sudeste de Itacuruba; (5f) - sulco em Luvissolo na porção nordeste de Itacuruba; $(5 \mathrm{~g})$ - sulco em Neossolo Litólico na porção nordeste de Itacuruba; (5h) e (5i) - sulcos em Luvissolo na porção sul de Itacuruba.

Na porção sul do município, realizaram-se 19 medições em sulcos (Figura 4d). Nos Planossolos, avaliaram-se 9 sulcos que apresentaram comprimento variando entre 8 e $26 \mathrm{~m}$, largura entre 0,3 e 3,7 
$\mathrm{m}$ e profundidade entre 0,2 e $0,6 \mathrm{~m}$. Nos Luvissolos, mediram-se 10 sulcos, com comprimento variando entre 8 e $42 \mathrm{~m}$, largura entre 0,9 e $5,5 \mathrm{~m}$ e profundidade entre 0,3 e $0,9 \mathrm{~m}$. Nessa porção ocorreu um grande destaque nas profundidades e comprimentos verificados, um exemplo desses sulcos pode ser verificado nas Figuras $5 \mathrm{~h}$ e $5 \mathrm{i}$.

Observou-se maior desenvolvimento horizontal nas feições encontradas, o que pode ter uma contribuição da pequena profundidade dos solos na região semiárida por seu baixo potencial hidrolítico. Segundo Corrêa, Souza e Cavalcanti (2014), a baixa umidade subterrânea no semiárido do Nordeste brasileiro conduz à fraca alteração por hidrólise, sendo predominante a ação do escoamento superficial difuso com forte intensidade, que pode evoluir a processos erosivos lineares.

Nas porções Nordeste, Central e Noroeste do município (Figura 5a), realizaram-se 33 medições, o que representa 47,15\% do total de medições, enquanto nas porções Sudeste e Sul (Figura 5a), mediram-se 37 sulcos, representando 52,85\% das medições realizadas. De modo geral, houve destaque para a ocorrência da erosão em sulcos nos Planossolos e Luvissolos, com exceção da porção Nordeste, onde o desenvolvimento maior desse processo foi nos Neossolos Litólicos, apesar de serem solos rasos (Figura $5 \mathrm{~g}$ ). Nas porções Sudeste e Sul de Itacuruba, foi possível observar a maior frequência de sulcos nos Planossolos. No entanto, na porção Sul, os sulcos apresentaram maiores comprimentos e profundidades. Têm-se, como exemplo, sulcos em Luvissolos que apresentaram $31 \mathrm{~m}$ (Figura 5h) e 42 $\mathrm{m}$ de comprimento e 0,7 (Figura $5 \mathrm{i}$ ) e $0,9 \mathrm{~m}$ de profundidade.

\section{Considerações Finais}

Nos principais solos do município, onde se destacam os Planossolos, Luvissolos e Neossolos Litólicos, há fortes processos erosivos que variaram de moderado a forte em $84 \%$ dos pontos avaliados.

A erosão em sulcos também é frequente em Itacuruba, com destaque onde ocorrem Planossolos e Luvissolos. Entre as medições realizadas, concentram-se nas porções sudeste e sul de Itacuruba 52,85\%, com maior frequência nos Planossolos, porém, o maior destaque em comprimento e profundidade observou-se nos Luvissolos.

A redução da cobertura vegetal, assim como a pequena utilização dos solos por práticas agrícolas evidenciam o processo de degradação ambiental instalado na área. É importante ressaltar que nem o clima e nem os solos são favoráveis ao uso agrícola. O processo de degradação instaurado na área fica bem evidenciado pelos processos erosivos bem avançados que dificultam a restauração da vegetação e a utilização das terras. 


\section{Agradecimentos}

Ao Grupo de Sensoriamento Remoto e Geoprocessamento - SERGEO do Departamento de Ciências Geográficas - DCG- UFPE, pela disponibilização do software utilizado neste trabalho e à Embrapa Solos UEP- Recife, pelo enorme apoio científico conferido na execução das pesquisas no semiárido de Pernambuco.

\section{Bibliografia}

ADIMASSU, Z. et al. Farmes' perceptions of land degradation and their investments in land mangement: a case study in the Central Rift Valley of Ethiopia. Environmental Management, v. 51, p. 989-998, 2013.

BARboSA NETO, M. V.; ARAÚJO, M. S. B.; ARAÚJO FILHO, J. C. Avaliação do uso da terra, degradação dos solos e análise multitemporal da cobertura vegetal no semiárido pernambucano. In: XXXV Congresso Brasileiro de Ciência do Solo. Natal - RN. Anais. 2015. P.1-4.

BELTRÃO, B. A. et al. Projeto cadastro de fontes de abastecimento por água subterrânea: diagnóstico do município de Itacuruba, estado de Pernambuco. Recife: CPRM/PRODEEM, 2005. 11 p.

BEZERRA, S. A. et al. Características hidráulicas da erosão em sulcos em um cambissolo do semiárido do Brasil. Revista Brasileira de Ciência do Solo, v. 34, p. 1.325-1.332, 2010.

BRASIL. Ministério do Meio Ambiente dos Recursos Hídricos e da Amazônia Legal. Mapa da ocorrência da desertificação e áreas de atenção especial. Brasília: Plano Nacional de Combate à Desertificação, 1998b.

CORREAA, A. C. B.; SOUZA, J. O. P.; CAVALCANTI, L. C. S. Solos do ambiente semiárido brasileiro: erosão e degradação a partir de uma perspectiva geomorfológica. In: GUERRA, A. J. T.; JORGE, M. C. O. Degradação dos solos no Brasil. Rio de Janeiro: Bertrand Brasil, 2014. p. 127-169.

EMBRAPA. Centro Nacional de Pesquisa de Solos. Sistema brasileiro de classificação de solos. 3. ed. Rio de Janeiro, 2013. 353 p.

IBGE. Informações sobre os municípios brasileiros: Itacuruba. Cidades@, 2015. Disponível em: <http://ibge.gov.br/cidadesat/xtras/perfil.php?lang=\&codmun=260740>. Acesso em: 20 mar. 2015.

GIONGO, V. et al. Carbono do sistema solo-planta no semiárido brasileiro. Revista Brasileira de Geografia Física, v. 6, p. 1.233-1.253, 2011.

KAIRIS, O. et al. Evaluation and selection of indicators for land degradation and desertification monitoring: types of degradation, causes, and implications for management. Environ Manage, v. 54, n. 5, p. 971-982, Nov. 2014.

LAL, R. Soil erosion and the global carbon budget. Environment International, v. 29, p. 437-450, 2003.

MARZOLFF, I. et al. Sustainability of land reclamation measures in erosional badlands: A comparative perspective on semi-arid landscapes of South Morocco and Central India. Geophysical Research Abstracts. Vol. 17, EGU2015-9825, 2015.

SAMPAIO, E. V. S. B. et al. Desertificação no Brasil: conceitos, núcleos e tecnologias de recuperação e convivência. Recife: Ed. Universitária da UFPE, 2003. 202 p.

SANTOS, R. D. et al. Manual de descrição e coleta de solo no campo. 5. ed. Viçosa, MG: Sociedade Brasileira de Ciência de Solo, 2005. 100 p. 
SILVA, F. B. R. et al. Zoneamento agroecológico de Pernambuco - Zape. Recife: Embrapa Solos - Unidade de Execução de Pesquisa e Desenvolvimento (UEP), 2001. (Embrapa Solos. Documentos, n. 35). ZAPE Digital. 1 CD-ROM.

TRIGUEIRO, E. R. C.; OLIVEIRA, V. P. V.; BEZERRA, C. L. F. Indicadores biofísicos e a dinâmica da degradação/desertificação no bioma caatinga: estudo de caso do município de Tauá, Ceará. REDE: Revista Eletrônica da Rede Prodema, Fortaleza, v. 3, n. 1, p. 62-82, 2009. 